\title{
Cytologic and Histologic Diagnosis and Significance of Controversial Squamous Lesions of the Uterine Cervix
}

\author{
Máire A. Duggan, M.D. \\ Department of Pathology and Laboratory Medicine, University of Calgary, and Calgary Laboratory \\ Services, Calgary, Alberta, Canada
}

The interpretation and precise classification of abnormal squamous cell changes in cervicovaginal smears (Pap tests) and tissue samples are challenging and controversial. The cytologic category atypical squamous cells of undetermined significance and the newly described squamous lesions atypical immature metaplasia, papillary immature metaplasia, and transitional cell metaplasia are representative. Their current status is reviewed, and future directions aimed at resolving some of the controversy and challenge are suggested.

KEY WORDS: Atypical immature metaplasia, Atypical squamous cells of undetermined significance, Literature review, Papillary immature metaplasia, Transitional cell metaplasia.

Mod Pathol 2000;13(3):252-260

The traditional concept that cervical squamous premalignancy encompasses a spectrum of disordered cell growth and maturation progressing over time from a low-grade to a high-grade squamous intraepithelial lesion (SIL) is being challenged by evidence that suggests that most low-grade lesions represent a self-limited human papillomavirus (HPV) infection and that high-grade lesions are a legitimate premalignancy $(1,2)$. The goal of cervical cancer screening is to detect the abnormal cells of premalignant lesions; until this alternative pathogenetic pathway is completely proved and generally accepted, screening for low $(\mathrm{L})$ and high $(\mathrm{H})$ grade SIL remains standard laboratory practice (3). The detection and precise classification of these cell changes in the Papanicolaou stained, cervicovaginal smear (Pap test) is controversial and challenging $(3,4)$. Contributing factors include the many lesions whose desquamated cells defy classification; underrepresentation of the abnormal lesion as

Copyright (C) 2000 by The United States and Canadian Academy of Pathology, Inc

VOL. 13, NO. 3, P. 252, 2000 Printed in the U.S.A.

Date of acceptance: November 8, 1999.

Address reprint requests to: Dr. Máire A. Duggan, Department of Pathology and Laboratory Medicine, Foothills Hospital, 1403 29th Street N.W., Calgary, T2N 2T9, Alberta, Canada.

a result of sampling error; smearing, preparation, and staining artifacts that alter cells; and cells of premalignant and malignant lesions that mimic benign lesions and vice versa.

Traditionally, the tissue result has been the gold standard against which the accuracy of cytopathology is measured (5). Because sampling error and lesion regression account for many noncorrelating cytologic-histologic samples, there is a growing acceptance of consensual peer review of the Pap test as the accuracy standard. Inconsistencies between histopathologic and cytopathologic reporting terminologies and lack of standardized histopathologic criteria with poor inter- and intraobserver reproducibility rates are additional reasons for this diminishing confidence in the tissue result as the gold standard (6). The cytologic category atypical squamous cells of undetermined significance (ASCUS) and the newly described squamous lesions atypical immature metaplasia, papillary immature metaplasia, and transitional cell metaplasia exemplify these controversies and challenges.

\section{ATYPICAL SQUAMOUS CELLS OF UNDETERMINED SIGNIFICANCE}

The Bethesda System (TBS) for reporting cervi$\mathrm{cal} /$ vaginal cytologic diagnoses was developed at a workshop sponsored by the National Cancer Institute in 1988 to provide a uniform diagnostic terminology that would facilitate communication between the laboratory and the clinician (7). The terminology was evaluated and modified in 1991, and further modifications are expected after the next workshop in $2001(8,9)$. In TBS, squamous abnormalities are classified as (1) ASCUS, (2) LSIL, (3) HSIL, and (4) squamous cell carcinoma. ASCUS is defined as "squamous cell abnormalities that are more marked than those attributable to reactive changes but that quantitatively and qualitatively fall short of a definitive diagnosis of SIL" (8). Because the cellular changes in the ASCUS category may reflect an exuberant benign change or a potentially serious lesion that cannot be unequivo- 
cally classified, they are interpreted as being of undetermined significance. Qualification of the atypia in favor of reactive, SIL/malignant, or unspecified is recommended but not required.

The need for described and illustrated cytologic criteria of TBS terminology was realized and later became available in the monograph of Kurman and Solomon (10). The monograph did not provide any guidelines regarding the qualification of the ASCUS into reactive, SIL/malignant, and unspecified categories, however. ASCUS in the reproductive woman was defined by a number of criteria. The principal one was nuclear size using either an intermediate squamous cell nucleus or a mature metaplastic squamous cell nucleus as the reference standard. An ASCUS nucleus was 2.5 to 3 times the size of an intermediate cell nucleus or 1.5 times the size of a mature metaplastic cell nucleus (Fig. 1). Although nuclear size was the most important feature, other nuclear and cytoplasmic features quantitatively and qualitatively intermediate between benign cellular changes (BCC) and LSIL, as well as those categorized as nonkoilocytotic HPV-related atypia, were included (Table 1). SIL in the postmenopausal smear is difficult to assess because squamous "atypia" is commonplace and usually reflects the

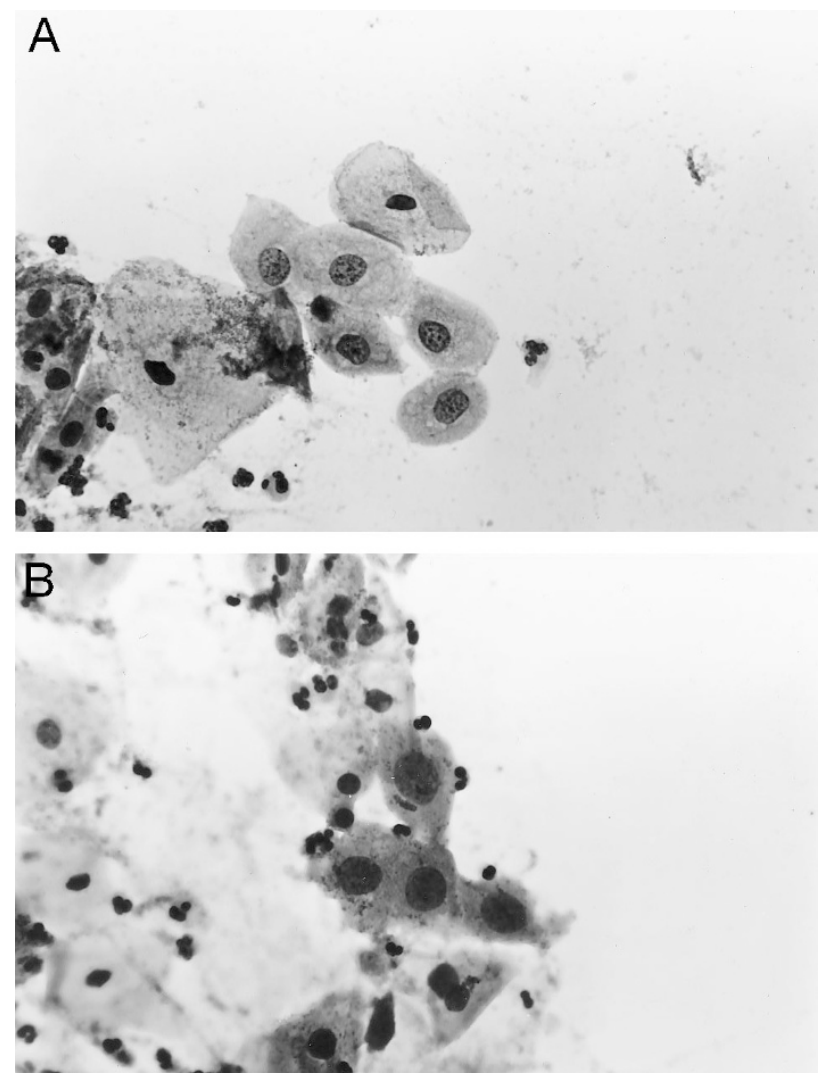

FIGURE 1. A, atypical squamous cells of undetermined significance in mature squamous cells demonstrating a mild degree of nuclear enlargement, hyperchromasia, and membrane irregularity. B, atypical squamous cells of undetermined significance in mature metaplastic squamous cells demonstrating nuclear enlargement.
TABLE 1. BCC Versus ASCUS Versus LSIL: Nuclear and Cytoplasmic Features

\begin{tabular}{lccc}
\hline \multicolumn{1}{c}{ Feature } & BCC & ASCUS & LSIL \\
\hline Nuclear & & & \\
$\quad$ Variation, size & - & $+/-$ & + \\
Variation, shape & - & $+/-$ & + \\
Chromatin & + fine & $+/-$ fine & $+/-$ coarse \\
Hyperchromasia & + & + & ++ \\
Smudgy chromatin & - & $+/-$ & + \\
$\quad$ Nucleolar prominence & + & - & $+/-$ \\
Cytoplasmic & & & \\
$\quad$ Polychromasia & + & - & - \\
Vacuolization & + & - & - \\
Perinuclear halos & $+/-$ & $+/-$ & $+/-$ \\
Thick rim of cytoplasm & - & $+/-$ & $+/-$ \\
$\quad$ Orangeophilia & $+/-$ & $+/-$ & $+/-$ \\
\hline
\end{tabular}

BCC, benign cellular changes; ASCUS, atypical squamous cells of undetermined significance; LSIL, low-grade squamous intraepithelial lesion; + , present; -, absent.

variable hypoestrogenic state. Kurman and Solomon (10) defined ASCUS in this scenario as a doubling of the nuclear size (Fig. 2).

Despite the publication of the TBS monograph, reproducibility of the ASCUS category was poor (11). In a 1992 review of 13 cases of ASCUS by the College of American Pathologists cytopathology committee, there was agreement in $62 \%$ of cases. In a second survey in 1994, the committee reviewed 31 cases of ASCUS; only $23 \%$ of cases were interpreted as ASCUS by more than $70 \%$ of the 17 members. In a study of 200 cases of ASCUS published in 1994, a five-member expert panel of cytopathologists did not agree on a single ASCUS case (12). Reproducibility in these studies likely was compromised by threshold variation among individuals in the classification of abnormal cells so that tests with cell abnormalities that were representative of a variety of cervical lesions were being categorized as ASCUS. Because the experts could not agree, it was unrealistic to expect that routine laboratory practice would be any better and confidence in the laboratory interpretation of the Pap test was seriously undermined.

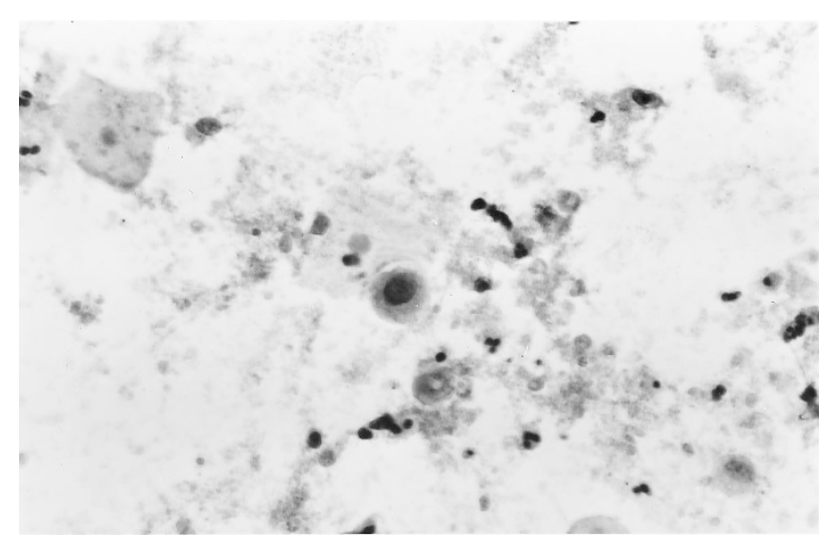

FIGURE 2. Atypical squamous cells of undetermined significance in an atrophic smear demonstrating nuclear enlargement. 
In the pre-TBS era, it was generally accepted that a Pap test with premalignant or malignant cell changes was abnormal. TBS redefined the abnormal threshold by creating the ASCUS category. A College of American Pathologists survey highlighted the high frequency and wide range of ASCUS reporting among 900 participating laboratories (13). The median ASCUS rate in 1993 was $2.8 \%$ (min:max, $1.6: 9.2$ ), with $10 \%$ of laboratories reporting rates higher than $9 \%$. Because the ASCUS rate was directly proportional to the laboratory's LSIL rate, the ratio of ASCUS to SIL diagnoses was concluded to be a more meaningful indicator of laboratory compliance with diagnostic criteria. The median ratio was 3:1 (min:max, 0.8:2.8) and is currently the standard for laboratories. The survey also demonstrated variable compliance with the recommendation for qualifying the likely cause of the atypia and the inclusion of a management recommendation. The ASCUS was qualified by $93 \%$ of laboratories to some degree; however, only $24 \%$ did it consistently. The same pattern was found when the inclusion of management recommendations was surveyed. This was included some or all of the time by $94 \%$ of laboratories, but only $29 \%$ did it consistently. Coincidental with the introduction of TBS terminology, the ASCUS category tripled the number of abnormal Pap tests, but opportunities to assist health care providers in guiding patient care were taken inconsistently by the laboratory practitioners. The false-negative threshold was redefined by the creation of the ASCUS category, and this increased the number of false-negative tests and claims of laboratory malpractice (14). The stage was thus set for a groundswell of negative opinion regarding the significance of the ASCUS category (15, 16).

Follow-up cytologic-histologic correlation studies failed to identify a histopathologic ASCUS counterpart and have fueled the developing negative opinion. Benign, premalignant, and malignant lesions desquamated cells that on Pap tests were being classified as ASCUS. Between 1994 and 1997, approximately 12 published studies reported the histopathology of ASCUS (17-28). In aggregate, the median (mean) sample size was 112 (220) cases (min:max, 31:782). The median overall SIL rate was $37.2 \%$ and the median HSIL rate was $11.5 \%$ (Table 2). There were approximately six studies identified in the same time period that qualified the ASCUS (17, 18, 25, 29-31). Individualistic criteria were used, as the monograph of Kurman and Solomon (10) had not provided guidelines for this exercise. The median (mean) sample size was 570 (505) cases (min:max, 118:1293). Unspecified was the most frequent qualifier, followed by SIL, and the least frequent was reactive (Table 3). Those that qualified as SIL had the highest median rates of SIL and HSIL in
TABLE 2. Detection of Biopsy-Confirmed SIL in Women with ASCUS: A Compilation of 3645 Cases from 12 Reported Studies (17-28)

\begin{tabular}{lcc}
\hline & SIL (\%) & HSIL (\%) \\
\hline Mean & 41 & 12.5 \\
Median & 37.2 & 11.5 \\
Min:Max & $29.7-61$ & $3-25$ \\
\hline
\end{tabular}

SIL, squamous intraepithelial lesion; HSIL, high-grade squamous intraepithelial lesion; Min, minimum; Max, maximum.

TABLE 3. Women with ASCUS Qualified as Reactive, SIL, or Unspecified: A Compilation of 3390 Cases from Six Published Studies (17, 18, 25, 29-31)

\begin{tabular}{lccc}
\hline & Reactive (\%) & SIL (\%) & Unspecified (\%) \\
\hline Mean & 20.3 & 29.3 & 50.4 \\
Median & 30.3 & 36 & 62.5 \\
Min:Max & $8.1-55.6$ & $21.7-51$ & $0-70.2$ \\
\hline
\end{tabular}

ASCUS, atypical squamous cells of undetermined significance; SIL, squamous intraepithelial lesion; Min, minimum; Max, maximum.

follow-up studies (36.0\% and 9.6\%, respectively), and those that qualified as reactive had the lowest (Table 4). Qualification of the ASCUS as a SIL was thus useful in that it better predicted smears that represented an SIL.

Since the introduction of ASCUS to laboratory practice in 1991, the management of it has been controversial. Management choices mainly include immediate colposcopy, follow-up interval Pap tests, or colposcopy after a second abnormal Pap test result of ASCUS or higher (32-37). Because a proportion of women had coincidental SIL or were at risk for developing SIL, reflex referral to colposcopy was almost routine practice. The increased referral for colposcopic examination of women who mostly had a normal cervix, a benign lesion, or an LSIL raised concerns about overtreatment and the expenditure of health care resources. Treatment of an ASCUS rate of $2 \%$ was estimated to cost an additional $\$ 1$ billion annually in the United States (16). Cost-effectiveness principles were not being met because this investment was not accompanied by an appreciable decrease in the incidence of cervical cancer. These concerns compounded the negative

\begin{tabular}{|c|c|c|c|c|c|c|}
\hline & \multicolumn{2}{|c|}{ Reactive } & \multicolumn{2}{|c|}{ SIL } & \multicolumn{2}{|c|}{ Unspecified } \\
\hline & $\begin{array}{l}\text { SIL } \\
(\%)\end{array}$ & $\begin{array}{c}\text { HSIL } \\
(\%)\end{array}$ & $\begin{array}{l}\text { SIL } \\
(\%)\end{array}$ & $\begin{array}{c}\text { HSIL } \\
(\%)\end{array}$ & $\begin{array}{l}\text { SIL } \\
(\%)\end{array}$ & $\begin{array}{c}\text { HSIL } \\
(\%)\end{array}$ \\
\hline Mean & 16.3 & 1.1 & 37 & 8.2 & 17.4 & 1.9 \\
\hline Median & 15 & 0 & 36 & 9.6 & 26.2 & 0 \\
\hline Min:Max & $8.6-29.5$ & $0-3$ & $15-52.5$ & $0-15$ & $0-33$ & $0-6.8$ \\
\hline
\end{tabular}

ASCUS, atypical squamous cells of undetermined significance; SIL, squamous intraepithelial lesion; HSIL, high-grade squamous intraepithelial lesion; Min, minimum; Max, maximum. 
opinion and led to widespread poor acceptance of the ASCUS term by health care providers.

More recent, this negative opinion has diminished and ASCUS has been accepted as a surrogate marker of cervical premalignancy/malignancy. The main priority of the laboratory therefore should be to separate smears that have a coincidental SIL or are at risk for progressing to an SIL from those that are benign lesions. A number of strategies could accomplish this goal. A reduction in the number of ASCUS smears could be achieved by excluding the nonkoilocytotic HPV changes from the category. In terms of pathogenesis and disease outcome, it would be more meaningful to include these abnormal smears in the LSIL category. More accurate and reproducible cytologic criteria, particularly with regard to qualifying the ASCUS, would also be advantageous. The recent study of Abati et al. (38) addressed the reliability of the published criteria of Kurman and Solomon (10) in the classification of atypia in postmenopausal smears and found a nuclear size 3 to 4 times normal to be a better predictor of SIL.

In an effort to identify cell changes that are predictive of SIL, Sheils and Wilbur (39) proposed a subcategorization of ASCUS on the basis of the maturity of the atypical squamous cell. In this approach, atypia is categorized as occurring in mature squamous cells, metaplastic squamous cells, and immature, metaplastic squamous cells (Fig. 3). Among their 296 smears with follow-up cytology and/or biopsy specimens, atypia in immature, metaplastic squamous cells was the best predictor of SIL (42\%) and in particular of HSIL (60\%). Most atypia occurred in mature squamous cells and was infrequent in immature metaplastic cells, however. Because of this distribution of morphologic cell types, most atypia among the 40 (13.5\%) women with an SIL and the 15 (5\%) with an HSIL in follow-up studies was in mature squamous cells (Fig. 4). These results suggest that atypia in mature

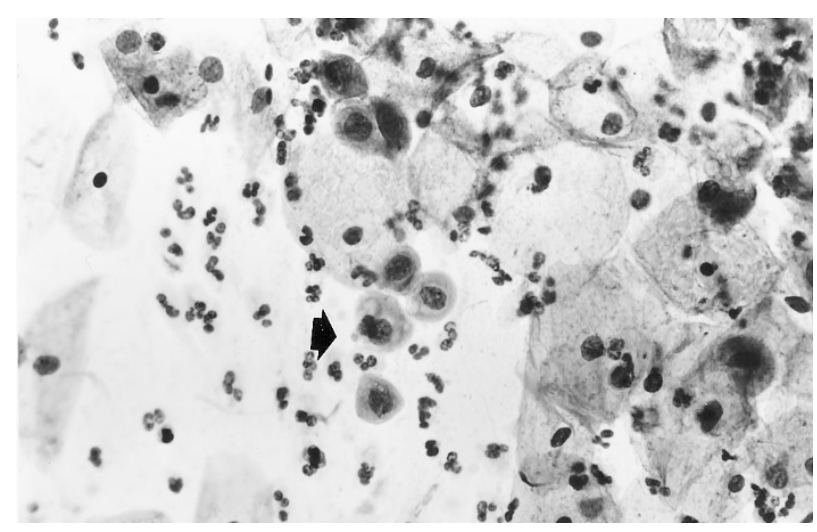

FIGURE 3. Atypical squamous cells of undetermined significance in immature, metaplastic squamous cells (arrow) demonstrating nuclear enlargement, hyperchromasia, and irregular nuclear membranes. squamous cells should not be discounted. As well, the relatively low rates of SIL (13.5\%) and HSIL (5\%) in follow-up studies contrasts sharply with means of $37 \%$ and $8.2 \%$, respectively, when the ASCUS is qualified as favoring an SIL per TBS (Table 4). Thus, it may be prudent to study why the TBS approach is a better predictor of SIL, before embracing the morphologic subclassification approach as the qualification standard.

Training and testing cytotechnologists and cytopathologists in the recognition and interpretation of new and refined cytologic criteria are essential. These criteria must be reproducible, and peer review should be implemented to maintain reproducibility within and between laboratories. Other quality assurance monitors to ensure accuracy, such as the ASCUS:BCC ratio, should be developed. Ancillary techniques such as ploidy or cytogenetic analysis, cell proliferation labeling, MN antigen expression, nuclear matrix protein expression, and HPV testing may have a role in clarifying ASCUS smears that show risk for SIL (40-45). HPV testing is the most promising candidate, and its role may soon be clarified by the ongoing National Cancer Institutesponsored ASCUS/LSIL Triage Study (46). Falsepositive results with ancillary techniques remain a concern, however. Thus, it is imperative that the efficacy of these techniques be demonstrated in controlled clinical trials and cost-effectiveness be established before routine implementation is considered.

Alternative screening technologies may be beneficial. Automated screening techniques, whether as primary screeners or postscreeners, and liquidbased cytology preparations have not eliminated the ASCUS category, however; for the most part, they have increased it (47-51). As these diagnostic approaches still require human interpretation, without further cytologic definition and/or a reliable ancillary test, the ASCUS controversy will be compounded by the adoption of this technology. Clear communication of the intent of the ASCUS result is essential, so qualification should be mandatory. Intent could also be reinforced by the consistent inclusion of an appropriate management recommendation. Because management with follow-up, interval Pap tests or colposcopy may be equally effective, the management decision should take into account such factors as the needs of the woman and the health care resources available to her (37).

\section{ATYPICAL IMMATURE METAPLASIA}

The term atypical immature metaplasia (AIM) was coined in 1983 to describe a squamous proliferation of the transformation zone and endocervical glands associated with abnormal Pap smears and a colpo- 


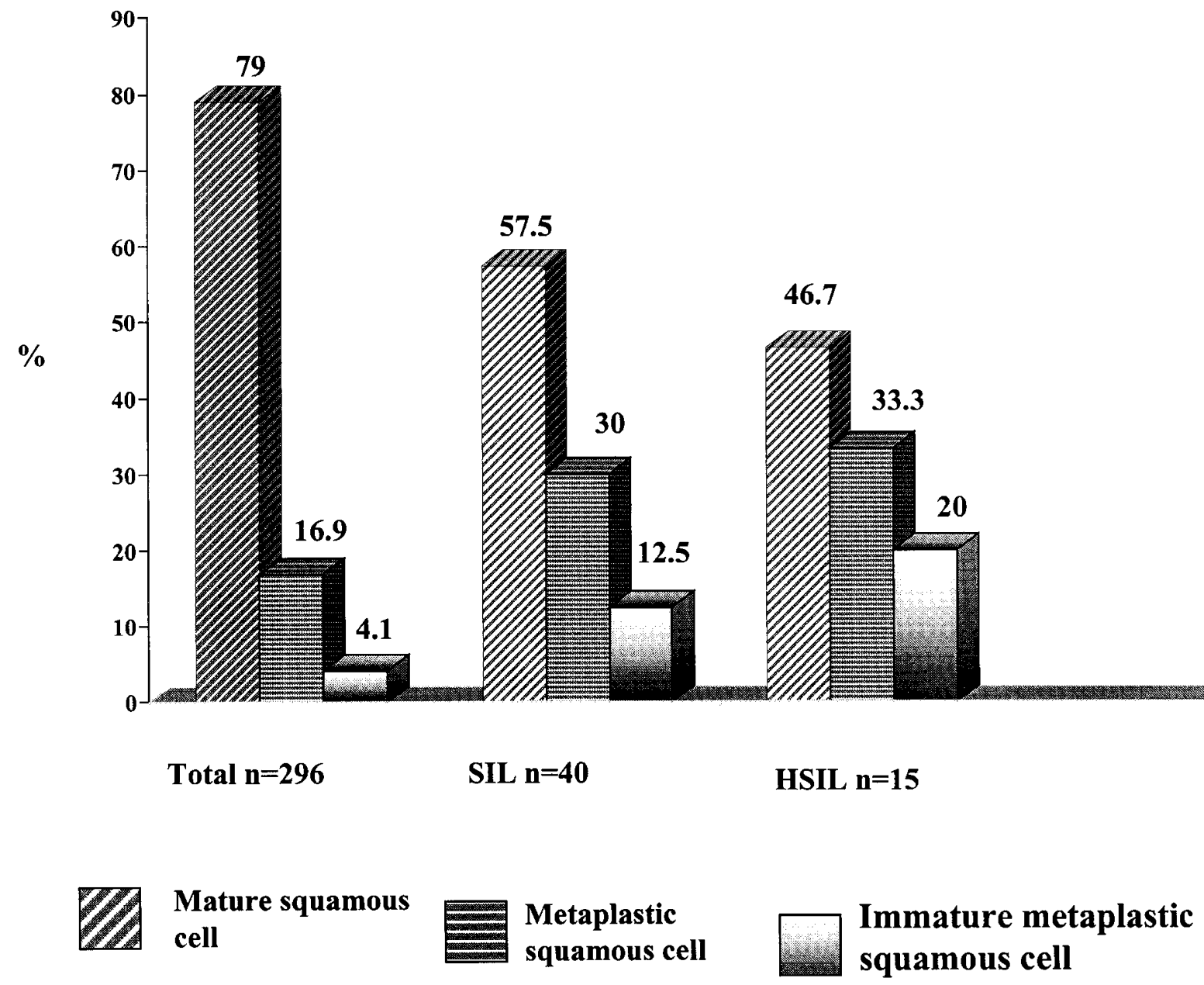

FIGURE 4. Morphologic cell type distribution in 296 women with atypical squamous cells of undetermined significance and in the $13.5 \%$ with squamous intraepithelial lesion and the $5 \%$ with high-grade squamous intraepithelial lesion in follow-up studies.

scopically visible abnormality (52). The lesion was characterized by a basal layer of uniform cells with a uniform chromatin pattern and variable hyperchromasia. The overlying squamous cells were monomorphic with prominent chromocenters and regular nuclear membranes (Fig. 5). Cell polarity was maintained and cell crowding and mitoses were rare. Mitoses when present were normal and confined to the lower third of the epithelium. Some lesions displayed higher mitotic rates, and some had multinucleation, nuclear enlargement, and perinuclear halos (Fig. 6). AIM shared histologic features with condyloma and cervical intraepithelial neoplasia (CIN) and was in transition with or coexisted with $34 \%$ of condylomas and $16 \%$ of CIN III. Because the age at presentation was similar to CIN I and HPV antigen was detected in $16 \%$, AIM was concluded to represent an HPV infection of immature, metaplastic squamous epithelium.

The diagnosis of AIM is difficult to make because of its histologic resemblance to CIN III and controversial because of uncertainty regarding its biologic and clinical significance. There are very few publications on the histology of AIM, but nuclear shape, chromatin pattern, and the intraepithelial location and type of mitoses seem to be reliable in distinguishing it from CIN III (Table 5). Recently, Geng et al. (53) compared the HPV DNA and cellular proliferation (Ki-67 index) status of AIM with that of the normal cervix, LSIL, and HSIL. They also determined the efficacy of HPV testing in predicting AIM outcome. Although there was overlap between categories, the average Ki-67 index of AIM was equal to LSIL but significantly higher than the normal cervix and lower than HSIL. High-risk HPV DNA was detected in $48 \%$ of AIM, and positive lesions were significantly more likely to have a subsequent HSIL diagnosis.

The evidence to date suggests that approximately $50 \%$ of AIM are HPV-related squamous proliferations of immature metaplastic epithelium $(52,53)$. Some lesions are benign, some are LSILs and HSILs, and some, particularly those that are HPV positive, are predictive of subsequent HSILs. The study by Park et al. (54) suggests that biology is not predicted by morphology, nor will it identify cases that are HPV positive. Thus, there may be a role for HPV testing and Ki-67 labeling to separate the benign lesions and confirm or predict the SILs. 


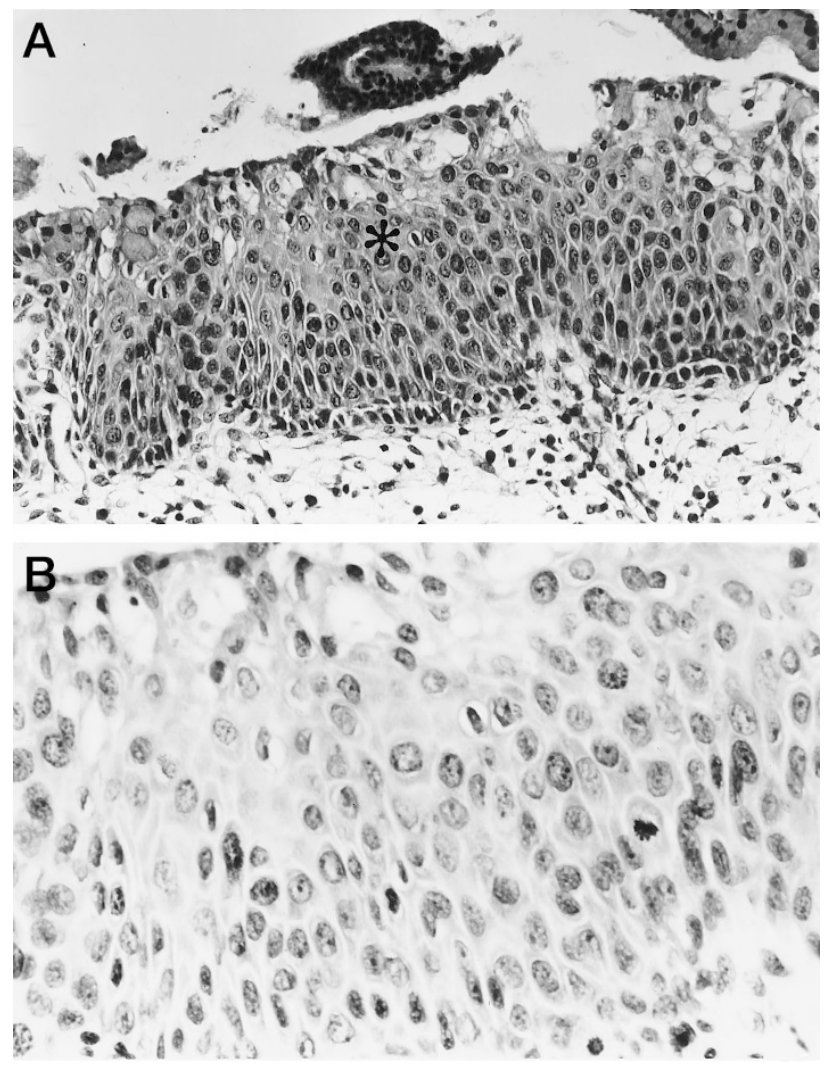

FIGURE 5. A, atypical immature metaplasia. The squamous metaplastic epithelium showing nuclear atypia, occasional perinuclear halos (asterisk), and a surface layer of mucinous epithelium. B, the hyperplastic epithelium showing a mitotic figure in the basal one third of the epithelium.

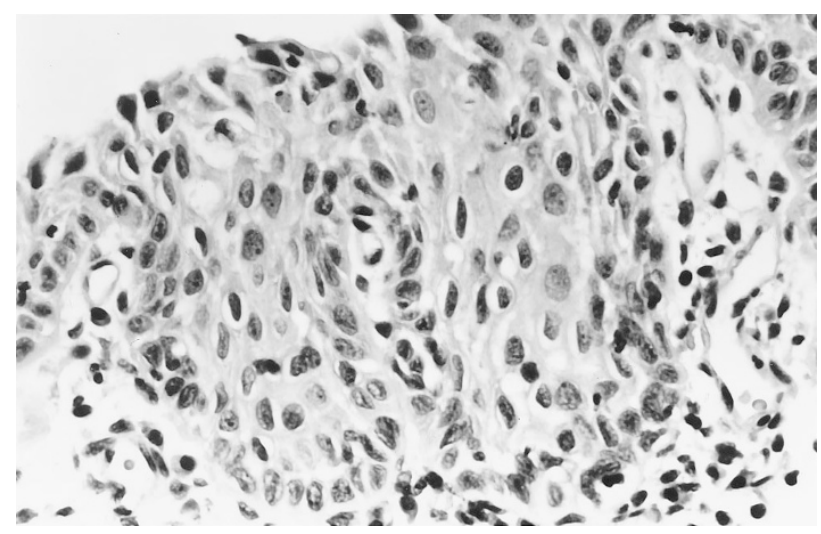

FIGURE 6. Atypical immature metaplasia. The squamous atypia can mimic a squamous intraepithelial lesion and show koilocytosis.

\section{PAPILLARY IMMATURE METAPLASIA}

Papillary immature metaplasia (PIM) is a recently described lesion of the proximal part of the transformation zone. In the seminal publication, the lesion was formed of papillae lined by a uniform population of immature metaplastic squamous cells (Fig. 7) (55). The papillae were either exophytic or endophytic. The immature cells showed mild nuclear atypia, mild anisonucleosis, or polychromasia, and mitoses were rare. Koilocytosis was variably present. The chromatin
TABLE 5. AIM Versus HSIL: Histopathologic Features

\begin{tabular}{lll}
\hline \multicolumn{1}{c}{ Feature } & \multicolumn{1}{c}{ AIM } & \multicolumn{1}{c}{ HSIL } \\
\hline Epithelial thickness & Increased & 8-12 layers \\
Cell maturation & Increased & - \\
Koilocytes & $+/-$ & $+/-$ \\
Mitosis & Lower $1 / 3$ & All layers \\
Abnormal mitoses & None & Present \\
Chromatin & Coarse/granular & Hyperchromatic \\
Nuclei & Round-oval & Oval-spindle \\
\hline
\end{tabular}

AIM, atypical immature metaplasia; HSIL, high-grade squamous intraepithelial lesion; +, present; -, absent.

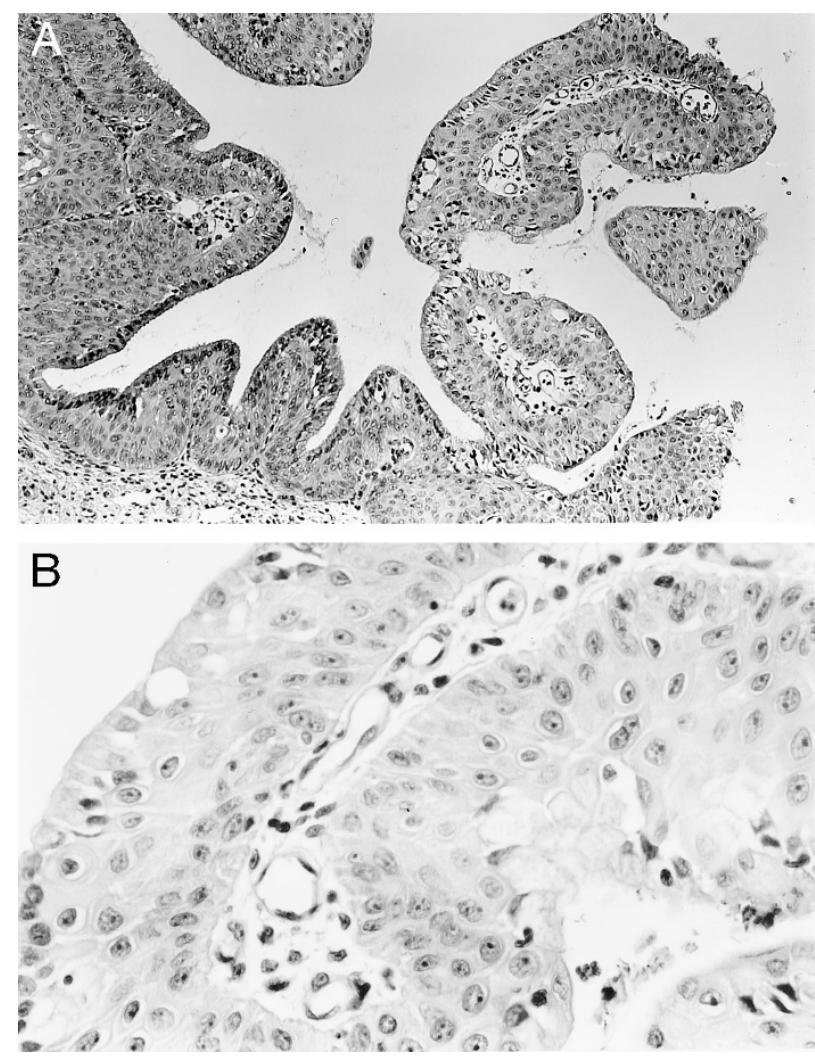

FIGURE 7. Papillary immature metaplasia. A, there is an exophytic proliferation of immature, metaplastic squamous epithelium. B, beneath the surface layer of mucinous epithelium is a proliferation of atypical immature, metaplastic squamous cells.

pattern was uniform and chromocenters were frequent. The overlying mucinous columnar epithelium sometimes was preserved. Most (83 to 70\%) lesions contained HPV DNA, and the lesion was infrequently associated with LSIL or HSIL. The Pap smear correlates of PIM consisted mostly of abnormal metaplastic squamous cells classified as ASCUS or LSIL (56). Their nuclei were round with an evenly distributed chromatin; regular nuclear membranes and koilocyte-like changes sometimes were seen. In contrast to the histology, chromocenters were not prominent. The morphologic appearance and HPV DNA data suggest that PIM is a variant of condyloma (LSIL). The biologic and clinical significance of the lesion is unknown, however, prompting the need for further study. 


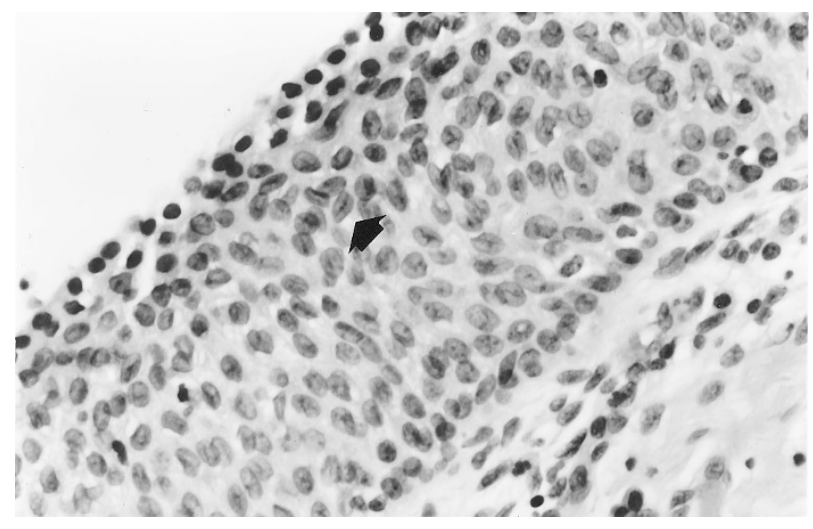

FIGURE 8. Transitional cell metaplasia. There is a surface layer of umbrellalike cells and a streaming proliferation of elongated nuclei. Note the nuclear grooves (arrow).

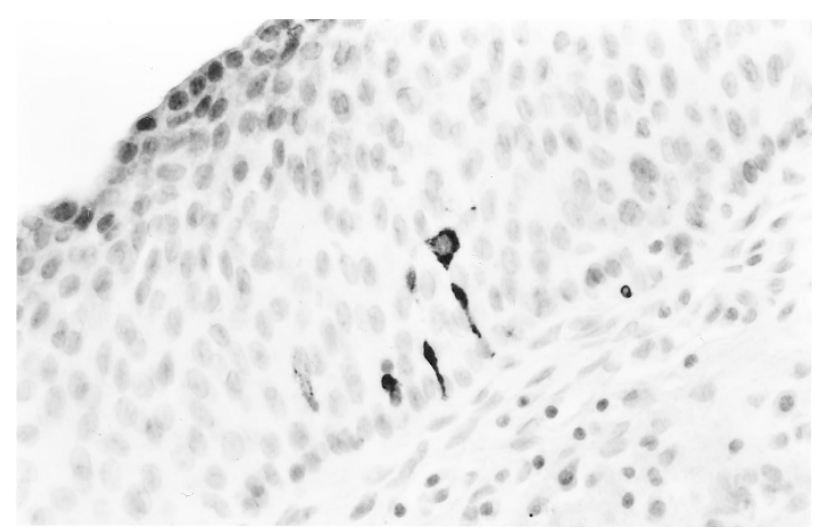

FIGURE 9. Transitional cell metaplasia. Elongated cells in the basal third of the epithelium showing serotonin immunoreactivity of the cytoplasm.

\section{TRANSITIONAL CELL METAPLASIA}

Transitional cell metaplasia (TCM) is a benign condition of the transformation zone, endocervical glands, and vagina developing in peri- or postmenopausal women $(57,58)$. The lesion is usually an incidental finding, although the Pap smear may have characteristic cell features (59). Histologically, the lesion may be confused with HSIL. In reported series, the lesion resembled hyperplastic urothelium and consisted of a proliferation ( $>10$ layers) of cells with oval- to spindle-shaped nuclei (Fig. 8). The nuclei were oriented vertically in the deeper layers. The surface layer resembled umbrella cells of the urothelium with horizontal orientation of the nuclei. Perinuclear halos were common. The nuclear: cytoplasmic ratio was low and mitoses were rare. The nuclei had irregular margins and contained a longitudinal groove. The basal cells stained positively with such neuroendocrine markers as calcitonin and serotonin and was useful in the exclusion of HSIL, which stains negatively (Fig. 9) (60). The growth pattern, nuclear:cytoplasmic ratio, chromatin pattern, and mitotic rate were useful in separating TCM from HSIL (Table 6).
TABLE 6. TCM Versus HSIL: Histopathologic Features

\begin{tabular}{lll}
\hline \multicolumn{1}{c}{ Feature } & \multicolumn{1}{c}{ TCM } & \multicolumn{1}{c}{ HSIL } \\
\hline Epithelial thickness & $>10$ layers & 8-12 layers \\
Growth pattern & Cell streaming & Cell disorganization \\
Mitosis & Rare/normal & Many/abnormal \\
n:c Ratio & Low & High \\
Chromatin & Fine & Hyperchromatic \\
Halos and grooves & & -
\end{tabular}

TCM, transitional cell metaplasia; HSIL, high-grade squamous intraepithelial lesion; n:c, nuclear:cytoplasmic; +, present; -, absent.

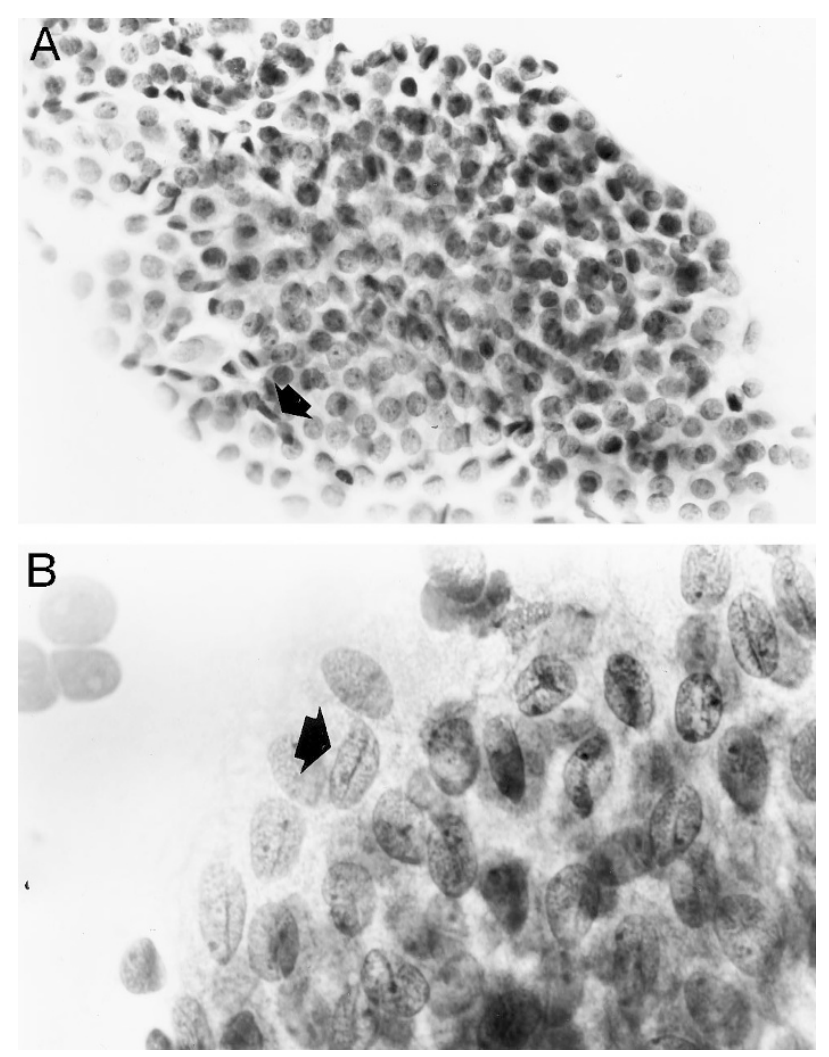

FIGURE 10. Transitional cell metaplasia. A, a sheet of overlapping cells with round uniform nuclei includes rows of umbrellalike cells $($ arrow). B, note the nuclear grooves (arrow).

TCM is a rare diagnosis by Pap smear. In a series of 31 women with TCM on biopsy and a review of their Pap smears, only $16 \%$ had characteristic cell changes (59). Most (79.5\%) smears were normal with the remainder being BCC, ASCUS, atypical glandular cells of undetermined significance, or SIL. Characteristic cytologic features included cohesive groups of streaming, spindle-shaped nuclei (Fig. 10). The nuclei had wrinkled contours and nuclear grooves were evident. To date, more than 100 cases of TCM have been reported, and although the cause is unknown, there is no evidence to indicate that the lesion is premalignant or is a surrogate marker of malignancy.

\section{CONCLUSIONS}

Without a doubt, uniform and standardized terminology for the classification of equivocal squa- 
mous atypias in Pap tests is needed. In the United Kingdom, the term "borderline nuclear change" without further qualification is used for this scenario, and in most parts of Australia, the terms "inconclusive for probable benign lesions" and "equivocal for probable premalignant/malignant lesions" are used. TBS is periodically revised, and the adoption of a morphologic subclassification of ASCUS is being considered for the next revision (9). Feedback from laboratory practitioners on this initiative is invited and should be provided. Although it is unlikely that the ASCUS term will disappear, restricting its use to label smears whose features are partially obscured by artifacts is preferable. A more meaningful term to communicate suspicion of an SIL in smears with well-preserved atypical squamous cells is welcome. Management, particularly in terms of deciding and prioritizing access to colposcopy, would be facilitated by qualifying this term as to whether the SIL was more likely to be of low or high grade. Pilot testing any changes in the terminology for impact to identify and resolve any issues before they are introduced into practice should be considered. Some of the controversy regarding ASCUS might have been avoided if this strategy had been adopted before TBS was regulated as standard laboratory practice.

Diagnostically difficult atypical squamous lesions such as AIM may need further study to better define histopathologic criteria. Routine application of HPV testing, Ki-67 labeling, cyclin E expression, or cytokeratin profiling to determine cause and biology of these atypical squamous lesions may be needed $(42,52,54,61,62)$. Consistency in reporting terminologies between cytopathology and histopathology is highly desirable and should be routinely adopted. Mechanisms to revise the reporting terminology so that it reflects the biology of newly characterized lesions should be developed.

Acknowledgment: Thanks go to Ms. Marge Gulutzan for her secretarial assistance.

\section{REFERENCES}

1. Richart JM. Cervical intraepithelial neoplasia: a review. In: Sommers S, editor. Pathology annual. East Norwalk, CT: Appleton-Century-Crofts; 1973. pp. 301-28.

2. Wright TC Jr, Kurman RJ. A critical review of the morphologic classification systems of preinvasive lesions of the cervix: the scientific basis for shifting the paradigm. Papillomavirus Report 1994;5:175-82.

3. Miller AB, Anderson GM, Brisson J, Laidlaw J, LePitre N, Malcolmson $\mathrm{P}$, et al. Report of a national workshop on screening for cancer of the cervix. Can Med Assoc J 1988; 145:1301-25.

4. Koss LG. The Papanicolaou test for cervical cancer detection: a triumph and a tragedy. J Am Med Assoc 1989;261:737-43.

5. Jones BA, Novis DA. Cervical biopsy-cytology correlation: a college of American Pathologists Q-probes study of 22439 correlations in 348 laboratories. Arch Pathol Lab Med 1996; 120:523-31.

6. Robertson AJ, Anderson JM, Swanson-Beck J, Burnett RA, Howatson SR, Lee FD. Observer variability in histopathological reporting of cervical biopsy specimens. J Clin Pathol 1989;42:231-8.

7. National Cancer Institute workshop. The 1988 Bethesda System for reporting cervical/vaginal diagnosis. J Am Med Assoc 1989;262:931-4.

8. The 1991 Bethesda system for reporting cervical/vaginal cytologic diagnosis. Diagn Cytopathol 1993;9:235-43.

9. Solomon D, Frable WJ, Vooijs GP, Wilbur DC, Amma NS, Collins RJ, et al. ASCUS and AGUS criteria: International Academy of Cytology Task Force summary. Diagnostic cytology towards the 21st century: an international expert conference and tutorial. Acta Cytol 1998;42:16-24.

10. Kurman RJ, Solomon D. Descriptive diagnosis: definitions, criteria, and explanatory notes. In: Kurman RJ, Solomon D, editors. The Bethesda System for reporting cervical/vaginal cytologic diagnosis: definitions, criteria and explanatory notes for terminology and specimen adequacy. New York: Springer-Verlag; 1994. pp. 9-18.

11. Robb JA. The “ASCUS” swamp. Diagn Cytopathol 1994;11:319-20.

12. Sherman ME, Shiffman MH, Lorincz AT, Manos MM, Scott DR, Kuman RJ, et al. Toward objective quality assurance in cervical cytopathology: correlation of cytopathologic diagnosis with detection of high-risk human papillomavirus types. Am J Clin Pathol 1994;102:182-7.

13. Davey DD, Nielsen ML, Naryshkin S, Robb JA, Cohen T, Kline TS. Atypical squamous cells of undetermined significance: current laboratory practices of participants in the College of American Pathologists Interlaboratory Comparison program in cervicovaginal cytology. Arch Pathol Lab Med 1996;120:440-4.

14. Frable WJ. Litigation cells: definition and observation on a cell type in cervical vaginal smears not addressed by The Bethesda System. Diagn Cytopathol 1994;11:213-5.

15. Wilbur DC. Atypical squamous cells of undetermined significance: is help on the way? Am J Clin Pathol 1996;105:661-4.

16. Jones HW III. Impact of The Bethesda System. Cancer 1995; 76(Suppl):1914-8.

17. Lachman MF, Cavallo-Calvanese C. Qualification of atypical squamous cells of undetermined significance in an independent laboratory: is it useful or significant? Am J Obstet Gynecol 1998;179:421-9.

18. Collins LC, Wang HH, Abu-Jawdeh GM. Qualifiers of atypical squamous cells of undetermined significance help in patient management. Mod Pathol 1996;9:677-81.

19. Abu-Jawdeh GM, Trawinski G, Wang HH. Histocytological study of squamous atypia on Pap smears. Mod Pathol 1994; 9:920-4.

20. Auger M, Charbonneau M, Arseneau J. Atypical squamous cells of undetermined significance: a cytohistologic study of 52 cases. Acta Cytol 1997;41:1671-5.

21. Ghoussoub RA, Rimm DL. Degree of dysplasia following diagnosis of atypical squamous cells of undetermined significance is influenced by patient history and type of followup. Diagn Cytopathol 1997;17:14-9.

22. Williams ML, Rimm DL, Pedigo MA, Frable WJ. Atypical squamous cells of undetermined significance: correlative histologic and follow-up studies from an academic medical center. Diagn Cytopathol 1997;16:1-7.

23. Lonky NM, Navarre GL, Saunders S, Sadeghi M, WoldeTsadik G. Low-grade Papanicolaou smears and The Bethesda System: a prospective cytohistopathologic analysis. Obstet Gynecol 1995;85:716-20.

24. Maier RC, Schultenover SJ. Evaluation of the atypical squamous cell Papanicolaou smear. Int J Gynecol Pathol 1986;5: 242-8. 
25. Lindheim SR, Smith-Nguyen G. Aggressive evaluation for atypical squamous cells in Papanicolaou smears. J Reprod Med 1990;35:971-3.

26. Widra EA, Dookhan D, Jordan A, McCue P, Bibbo M, Dunton CJ. Evaluation of the atypical cytologic smear: validity of the 1991 Bethesda System. J Reprod Med 1994;39:682-4

27. Selvaggi SM, Haefner HK. Reporting of atypical squamous cells of undetermined significance on cervical smears: is it significant? Diagn Cytopathol 1995;13:352-6.

28. Sidaway MK, Tabarra SO. Reactive changes and atypical squamous cells of undetermined significance in Papanicolaou smears: a cytohistological correlation. Diagn Cytopathol 1993;9:423-9.

29. Kline MJ, Davey DD. Atypical squamous cells of undetermined significance qualified: a follow-up study. Diagn Cytopathol 1996;14:380-4.

30. Gonzalez D, Hernandez E, Anderson L, Heller P, Atkinson BF. Clinical significance of a cervical cytologic diagnosis of atypical squamous cells of undetermined significance: favoring a reactive process or low grade squamous intraepithelial lesion. J Reprod Med 1996;41:719-23.

31. Magnan BJ, Steele CT, Powers CN. Atypical squamous cells: is subclassification worthwhile? Acta Cytol 1994;38:796.

32. Alanen KW, Elit LM, Molinoaro PA, McLachlin CM. Assessment of cytologic follow-up as the recommended management for patients with atypical squamous cells of undetermined significance or low grade squamous intraepithelial lesions. Cancer 1998;84:5-10.

33. Suh-Burgmann E, Darragh T, Smith-McCune K. Atypical squamous cells of undetermined significance: management patterns at an academic medical center. Am J Obstet Gynecol 1998;178:991-5.

34. Baldauf JJ, Ritter J. Comparison of the risks of cytologic surveillance of women with atypical cells of low-grade abnormalities on cervical smear: review of the literature. Eur J Obstet Gynecol Reprod Biol 1998;76:193-9.

35. Ferris DG, Wright TC Jr, Litaker MS, Richart RM, Lorincz AT, Sun XW, et al. Triage of women with ASCUS and LSIL on Pap smear reports: management by repeat Pap smear, HPV DNA testing, or colposcopy? J Fam Pract 1998;46:125-34.

36. Cecchini S, Iossa A, Bonardi R, Ciatto S, Cariaggi P. Comparing two modalities of management of women with cytologic evidence of squamous or glandular atypia: early repeat cytology or colposcopy. Tumori 1997;83:732-4.

37. Ferris DG, Kriegel D, Cote L, Litaker M, Woodward L. Women's triage and management preferences for cervical cytologic reports demonstrating atypical squamous cells of undetermined significance and low-grade squamous intraepithelial lesions. Arch Fam Med 1997;6:348-53.

38. Abati A, Jaffurs W, Wilder AM. Squamous atypia in the atrophic vaginal smear: a new look at an old problem. Cancer 1998;84:218-25.

39. Sheils LA, Wilbur DC. Atypical squamous cells of undetermined significance: stratification of the risk of association with, or progression to squamous intraepithelial lesions based on morphologic subcategorization. Acta Cytol 1997; 41:1065-72.

40. Palcic B, Garner DM, MacAulay CE. Image cytometry and chemoprevention in cervical cancer. J Cell Biochem 1995;23: 43-54.

41. Kurtycz D, Nunez M, Arts T, Bauman C, Harris C, Inhorn S, et al. Use of fluorescent in situ hybridization to detect aneuploidy in cervical dysplasia. Diagn Cytopathol 1996;15:4651.

42. Dunton CJ, van Hoeven KH, Kovatich AJ, Oliver RE, Scaheri RQ, Cater JR, et al. Ki-67 antigen staining as an adjunct to identifying cervical intraepithelial neoplasia. Gynecol Oncol 1997;64:451-5.

43. Liao SY, Stanbridge EJ. Expression of the MN antigen in cervical Papanicolaou smears is an early diagnostic biomarker of cervical dysplasia. Cancer Epidemiol Biomarkers Prev 1996;5:549-57.

44. Xu B, Keesee S, Meyer J, Oreper A, Potz D, Schellenberg Y, et $a l$. The use of NMP179, a unique nuclear matrix marker for prediction of behaviour in cases designated as ASCUS: a pilot study. Acta Cytol 1998;42:1226.

45. Wright TC Jr, Lorincz A, Ferris DG, Richart RM, Ferenczy A, Mielzynska I, et al. Reflex human Papillomavirus deoxyribonucleic acid testing in women with abnormal Papanicolaou smears. Am J Obstet Gynecol 1998;178:962-6.

46. Research Contracts Branch. Randomized trial on the clinical management of ASCUS and LSIL of the uterine cervixclinical centers. Request for proposal number NCI-CN55040-05. NIH Guide 23, No. 40, Nov. 18, 1994.

47. Mango LJ, Philip VT. Neural network-assisted and microscopic rescreening in presumed negative cervical cytologic smears. Acta Cytol 1998;42:227-31.

48. Mango LJ, Radensky PW. Interactive neural network assisted screening: a clinical assessment. Acta Cytol 1998;42:233-45.

49. Wilbur DC, Prey MU, Miller WM, Pawlick GF, Colgan TJ. The Autopap system for primary screening in cervical cytology: comparing the results of a prospective, intended use study with routine manual practice. Acta Cytol 1998;42:214-20.

50. Patten SF, Lee JSJ, Wilbur DC, Bonfiglio TA, Colgan TJ, Richart RM, et al. The AutoPap 300 QC System multicentre clinical trials for use in quality control rescreening of cervical smears: I. Prospective intended use study. Cancer 1997;81: 343-7.

51. Bolick DR, Hellman DJ. Laboratory implementation and efficacy assessment of the ThinPrep cervical cancer screening system. Acta Cytol 1998;42:209-13.

52. Crum CP, Egawa K, Fu Shi Y, Lancaster WD, Barron B, Levine $\mathrm{RU}$, et al. Atypical immature metaplasia (AIM): a subset of human papillomavirus infection of the cervix. Cancer 1983; 51:2214-9.

53. Geng L, Connolly DC, Isacson C, Ronnett BM, Cho KR. Atypical immature metaplasia (AIM) of the cervix: is it a precursor of HSIL? Mod Pathol 1998;11:105A.

54. Park IJ, Genest DR, Sun D, Crum CP. Atypical immature squamous metaplastic-type cervical proliferations: a histologic spectrum of uncertain etiology. Mod Pathol 1998;11:111A.

55. Ward BE, Saleh AM, Williams JV, Zitz JC, Crum CP. Papillary immature metaplasia of the cervix: a distinct subset of exophytic cervical condyloma associated with HPV-6/11 nucleic acids. Mod Pathol 1992;4:391-5.

56. Mosher RE, Lee KR, Trivijitsilp P, Crum CP. Cytologic correlates of papillary immature metaplasia (immature condyloma) of the cervix. Diagn Cytopathol 1998;18:416-21.

57. Egan AJM, Russell P. Transitional (urothelial) cell metaplasia of the uterine cervix: morphological assessment of 31 cases. Int J Gynecol Pathol 1997;16:89-98.

58. Weir MM, Bell DA, Young RH. Transitional cell metaplasia of the uterine cervix and vagina: an underrecognized lesion that may be confused with high-grade dysplasia. Am J Surg Pathol 1997;21:510-7.

59. Weir MM, Bell DA. Transitional cell metaplasia of the cervix: a newly described entity in cervicovaginal smears. Diagn Cytopathol 1998;18:222-6.

60. Fetisoff F, Dubois MP, Heitz PU, Lansac J, Arbeille-Brassart B, Jobard P. Endocrine cells in the female genital tract. Int J Gynecol Pathol 1986;5:75-87.

61. Quade BJ, Park JJ, Crum CP, Sun D, Dutta AN. In vivo cyclin E expression as a marker for early cervical neoplasia. Mod Pathol 1998;12:1238-46.

62. Smedts F, Ramaekers F, Robben H, Pruszczynski M, van Muijen G, Lane B, et al. Changing patterns of keratin expression during progression of cervical intraepithelial neoplasia. Am J Pathol 1990;136:657-68. 